\title{
Article
}

\section{TP53 Mutations as a Driver of Metastasis Signaling in Advanced Cancer Patients}

\author{
Ritu Pandey ${ }^{1,2, *}$, Nathan Johnson ${ }^{3}$, Laurence Cooke ${ }^{1}$, Benny Johnson ${ }^{4}$, Yuliang Chen ${ }^{1}$, Manjari Pandey ${ }^{5}$, \\ Jason Chandler ${ }^{5}$ and Daruka Mahadevan ${ }^{6, *}$ \\ 1 Cancer Center, University of Arizona, Tucson, AZ 85724, USA; lcookeaz@gmail.com (L.C.); \\ yuliangchen@email.arizona.edu (Y.C.) \\ 2 Department of Cellular and Molecular Medicine, University of Arizona, Tucson, AZ 85724, USA \\ 3 School of Medicine, Vanderbilt University, Nashville, TN 37325, USA; nathan.r.johnson@vanderbilt.edu \\ 4 MD Anderson Cancer Center, Houston, TX 77030, USA; bjohnson6@mdanderson.org \\ 5 West Cancer Center, 7945 Wolf River Blvd, Germantown, TN 38138, USA; mpandey@westclinic.com (M.P.); \\ jachandler@westclinic.com (J.C.) \\ 6 Mays Cancer Center, University of Texas Health San Antonio, San Antonio, TX 78229, USA \\ * Correspondence: ritu@email.arizona.edu (R.P.); mahadevand@uthscsa.edu (D.M.)
}

Citation: Pandey, R.; Johnson, N.; Cooke, L.; Johnson, B.; Chen, Y.; Pandey, M.; Chandler, J.; Mahadevan, D. TP53 Mutations as a Driver of Metastasis Signaling in Advanced Cancer Patients. Cancers 2021, 13, 597. https://doi.org/10.3390/ cancers13040597

Received: 7 December 2020

Accepted: 28 January 2021

Published: 3 February 2021

Publisher's Note: MDPI stays neutral with regard to jurisdictional claims in published maps and institutional affiliations.

Copyright: (C) 2021 by the authors. Licensee MDPI, Basel, Switzerland. This article is an open access article distributed under the terms and conditions of the Creative Commons Attribution (CC BY) license (https:// creativecommons.org/licenses/by/ $4.0 /)$.
Simple Summary: The DNA sequencing of cancer provides information about specific genetic changes that could help with treatment decisions. Tumors from different tissues change over time and acquire new genetic changes particularly with treatment. Our study analyzed the gene changes of 171 advanced cancer patients. We predicted that tumors gain new mutations but that TP53 mutations (guardian of the human genome) are conserved as the tumor progresses from primary to metastatic sites and across tissue types. We analyzed the primary and metastatic site gene changes in 25 tissue types and conducted in-depth analysis of colon and lung cancer sites for substantial changes. TP53 site specific mutations were different across tissue types and suggest different molecular changes. Other genetic changes that occur together with TP53 as drivers collectively alter how cells respond to signals which are important to tumor treatments.

Abstract: Molecular profiling with next generation sequencing (NGS) delivers key information on mutant gene sequences, copy number alterations, gene-fusions, and with immunohistochemistry (IHC), is a valuable tool in clinical decision making for patients entering investigational agent trials. Our objective was to elucidate mutational profiles from primary versus metastatic sites from advanced cancer patients to guide rational therapy. All phase I patients $(n=203)$ with advanced cancer were profiled by commercially available NGS platforms. The samples were annotated by histology, primary and metastatic site, biopsy site, gene mutations, mutation count/gene, and mutant TP53. A molecular profile of each patient was categorized into common and unique mutations, signaling pathways for each profile and TP53 mutations mapped to 3D-structure of p53 bound to DNA and pre/post therapy molecular response. Of the 171 patients analyzed, 145 had genetic alterations from primary and metastatic sites. The predominant histology was adenocarcinoma followed by squamous cell carcinoma, carcinoma of unknown primary site (CUPS), and melanoma. Of 790 unique mutations, TP53 is the most common followed by APC, KRAS, PIK3CA, ATM, PTEN, NOTCH1, BRCA2, BRAF, KMT2D, LRP1B, and CDKN2A. TP53 was found in most metastatic sites and appears to be a key driver of acquired drug resistance. We highlight examples of acquired mutational profiles pre-/ post- targeted therapy in multiple tumor types with a menu of potential targeted agents. Conclusion: The mutational profiling of primary and metastatic lesions in cancer patients provides an opportunity to identify TP53 driver 'pathways' that may predict for drug sensitivity/resistance and guide rational drug combinations in clinical trials.

Keywords: NGS; FISH; IHC; oncogenes; tumor suppressors; TP53; targeted therapy 


\section{Introduction}

'Precision oncology' or 'cancer genome medicine' is the seamless application of the Watson-Crick 'central dogma' to every patient with cancer (personalized therapy), where their tumor molecular profile (genome, proteome, epigenome, immunome, microenvironmentome, metabolome, etc.) may inform diagnosis, prognosis, and treatments. 'Precision therapeutics' of cancer implies mechanism of action-based targeting of the 'hallmarks' of cancer utilizing molecular taxonomy, genomic, proteomic in diagnosis and guiding therapeutics in well-designed innovative trials. The large-scale whole genome sequencing (WGS) of cancer such as the ICGC (International Cancer Genome Consortium) and TCGA (The Cancer Genome Atlas) have cataloged prevalent genomic alterations across a myriad of human malignancies [1,2], identifying recurrent genetic mutations that drive aberrant signaling pathways controlled by master regulators that lead to acquired targetable phenotypic characteristics [3]. With the advent of new molecular and cellular technologies, oncology has evolved from treating cancer patients with non-specific DNA-damaging and microtubule-targeted combination chemotherapy to molecular pathology-stratified histology agnostic immune checkpoint and targeted therapies.

Intra-tumor and spatially separated multiple sub-clone heterogeneity elegantly described in clear cell renal cancer and other malignancies are major contributors to the understanding of tumor evolution and drug resistance. Branched 'Darwinian' evolution [4] is a significant challenge to current therapies but should provide insights to mitigate or disrupt anticipated genetic alterations by a rationalized approach to precision therapeutics. Elucidating the mechanism of genomic alterations is likely to identify master regulators [5] once longitudinal tumor sampling with minimally invasive methods become a reality. Solid and liquid tumor biopsies during the course of therapy of a given cancer subtype are likely to inform decisions to switch tailored therapies that make mechanistic sense (e.g., TRACERxTracking Cancer Evolution through Therapy [6] in lung cancer [7]) and advanced cancer [8]. The current practice of stratifying patients to a single-diagnostic/single-drug will change as multiple biomarkers has become clinically actionable. The development of multi-biomarker assays coupled to NGS (DNA and RNA sequencing and single cell transcriptomics) will complement 'precision' diagnostics, prognostics, and therapeutics [9].

A major requirement of 'precision oncology' is hypothesis-driven research to improve patient outcomes [10]. NGS data have been utilized to conduct histology-agnostic 'umbrella' or 'basket' trials and one such trial sponsored by the NCI (MATCH trial) [11] where multiple histologies are matched by biomarkers to a targeted agent. A second approach uses a master protocol (S1400) within a single histology (e.g., squamous cell lung cancer) to test multiple omic-drug matches based on a defined set of genes. A third approach is a 'strategy' trial where patients are assigned a therapy based on their omics profile or physician's choice. The NCI has launched the 'The Molecular Profiling-based Assignment of Cancer Therapeutics' (M-PACT) [12] trial where patients are screened for actionable gene alterations and randomized to a drug that targets a mutated oncogene product or a drug chosen by a physician that does not correspond to a mutation or amplification. The primary endpoint is response rate and four-month progression-free survival. A fourth approach is an 'observational' trial utilizing off-label targeted therapies (Targeted Agent and Profiling Utilization Registry-TAPUR) [13]. A major challenge is analysis of large-scale genomic data for clinical application [14]. Whole-genome sequencing is an excellent strategy for comprehensive molecular profiling but requires validation for clinical utility. The currently available gene-capture platforms, when used to match therapies with whole exome, whole genome, and transcriptome (RNA-Seq), are in the domain of discovery research [15].

In unmatched and matched paired analysis of primary and metastatic tumors, TP53 appears to enrich to metastasis [16]. However, whether the cause and/or effect is due to chromosomal instability and/or drug resistance remains to be established [16]. In our 'New Therapeutics Program' all advanced cancer patients were molecularly profiled by NGS for mutations, copy number alterations (CNA), translocations (FISH/CISH), and IHC to inform clinical decisions for investigational agent trials. We hypothesized that for primary 
and metastatic sites, TP53 mutations are more frequent and appear to be a key driver of acquired drug resistance in advanced cancer patients. Mutation in TP53 is heterogeneous and are known to induce complex transcriptional changes effecting multiple biological responses [17]. Cellular responses to a specific TP53 mutation may depend on the tissue type, tumor stage and co-mutated genes. Thus, investigating the underlying p53 driven signaling pathways is predicted to provide opportunities to not only understand evolving pathobiology but also provide better guidance to rational drug therapies.

\section{Results}

\subsection{Primary and Metastatic NGS Profiling of Advanced Cancer Patients}

Of the 171 patients entering phase I clinical trials, 145 had genetic alterations with respect to the primary and metastatic site, histology, and total number of clinically relevant mutated genes (Table 1). In our cohort of patients, utilizing large NGS platforms probing 300 (Foundation One: 25\% Patients, 421 (Precipio: 36\% Patients), and 600 (Caris MI: 39\% Patients) cancer-related genes identified (a) common tumor types with a myriad of total unique mutations e.g., non-small cell lung cancer 85 mutations $(n=20)$, colon cancer 87 mutations $(n=28)$, breast cancer 79 mutations $(n=17)$, and ovarian cancer 51 mutations $(n=14)$; (b) common tumor types with a lower average number of uniquely mutated genes per patient e.g., non-small cell lung cancer $(n=3)$, colon cancer $(n=3)$, breast cancer $(n=4)$, and ovarian cancer $(n=3)$; (c) some tumor types have a higher number of unique mutated genes per patient e.g., anus ( $n=27$ mutations), CUPS ( $n=90$ mutations), esophagus $(n=54)$, prostate $(n=49$ mutations) and uterus $(n=38$ mutations $)$; $(\mathrm{d})$ common driver mutations per histologic type were for e.g., for colon cancer (TP53, APC, KRAS, PIK3CA, $B R A F, S M A D 4, S P T A 1)$, non-small cell lung cancer (TP53, EGFR, KRAS, PTEN, CDKN2A, NOTCH1, NTRK1), breast cancer (TP53, NOTCH1, PIK3CA, ARID1A, BRCA2, NF1, ABL1) and ovarian cancer (TP53, FLT4, ALK, ATM, BRAF, BRIP1, C11orf30) respectively.

Table 1. Molecular profiles of advanced cancer patients enrolling in phase I trials.

\begin{tabular}{|c|c|c|c|c|}
\hline Primary & Number of Patients & Histology & Number of Mutated Genes & Mutated Gene ID's \\
\hline Anus & 2 & Squamous Cell Carcinoma & 27 & $\begin{array}{c}\text { APC, ARID2, ASXL1, ATRX, CCND1, CDKN1B, } \\
\text { CDKN2A, EPHA5, ERBB2, ERBB4, FANCA, FGF19, } \\
\text { FGF4, FLT1, INHBA, MED12, KMT2D, MYCN, NKX2-1, } \\
\text { PALB2, PIK3CA, POLE, RARA, RB1, SMARCA4, } \\
\text { TERT, TSHR }\end{array}$ \\
\hline Appendix & 2 & Adenocarcinoma & 13 & $\begin{array}{c}\text { AR, CDK12, FGFR1, FLT3, GATA6, GNAS, KRAS, } \\
\text { KMT2A, KMT2C, NOTCH1, PRKDC, SMAD4, SPEN }\end{array}$ \\
\hline- & 1 & Mucinous Adenocarcinoma & 1 & KRAS \\
\hline Bladder & 2 & Transitional Cell Carcinoma & 24 & $\begin{array}{c}\text { ATM, CSMD3, EP400, EPHB4, FGFR3, FN1, LTF, MAF, } \\
\text { KMT2A, MSH6, MTR, MYH9, NUMA1, PDE4DIP, } \\
\text { PDGFB, PDGFRa, PIK3C2B, PIK3CA, PRKAR1A, PTEN, } \\
\text { SF3B1, THBS1, TP53, WRN }\end{array}$ \\
\hline Brain & 1 & Astrocytoma & 2 & $\begin{array}{c}\text { IDH1, TP53 } \\
\text { I }\end{array}$ \\
\hline- & 3 & Glioblastoma Multiforme & 16 & $\begin{array}{c}\text { AKT3, BRAF, EGFR, EGFRvIII, ERBB2, ETV4, FLT3, } \\
\text { KRAS, NF1, NOTCH2, PTEN, SMAD2, SMO, TNFAIP3, } \\
\text { TRRAP, UBR5 }\end{array}$ \\
\hline- & 1 & Medulloblastoma & 10 & $\begin{array}{c}\text { BCOR, CARD11, FAM123B, GNAS, LZTR1, KMT2D, } \\
\text { NRAS, RARA, SMO, TERT }\end{array}$ \\
\hline Breast & 17 & Adenocarcinoma & 79 & $\begin{array}{c}\text { FAT1, FGF19, LRP1B, KMT2D, NF2 } \\
\text { ABL1, ABL2, AKT1, AR, ARFRP1, ARID1A, ASXL1, } \\
\text { ATM, BARD1, BCL2L2, BCL9, BRCA2, CCNE1, CDH1, } \\
\text { CDK12, CDKN2A, CHD4, CHEK2, CIC, CREBBP, } \\
\text { CSMD3, DAXX, DDR2, DST, EGFR, EPHA3, ERBB4, } \\
\text { ESR1, FAM123B, FAT1, FGFR1, FGFR3, FH, FLT1, FLT3, } \\
\text { GATA3, GRIN2A, HSP90AB1, Her2/Neu, IDH2, JAK1, } \\
\text { JAK2, JAK3, KDM6A, KIT, KRAS, MAP2K4, MAPK8, } \\
\text { MST1R, MYCL1, MYST3, NF1, NFKB1, NOTCH1, } \\
\text { PARP1, PBRM1, PDGFRA, PDGFRB, PDGFRa, PIK3CA, } \\
\text { PIK3R2, PMS2, PRKCI, PTCH1, PTEN, PTPN11, PTPRD, } \\
\text { RET, RPS6KA2, RUNX1, SDHA, SGK1,TGM7, TLR4, } \\
\text { TNK2, TOP2A, TP53, TPR, TSC1 }\end{array}$ \\
\hline
\end{tabular}


Table 1. Cont.

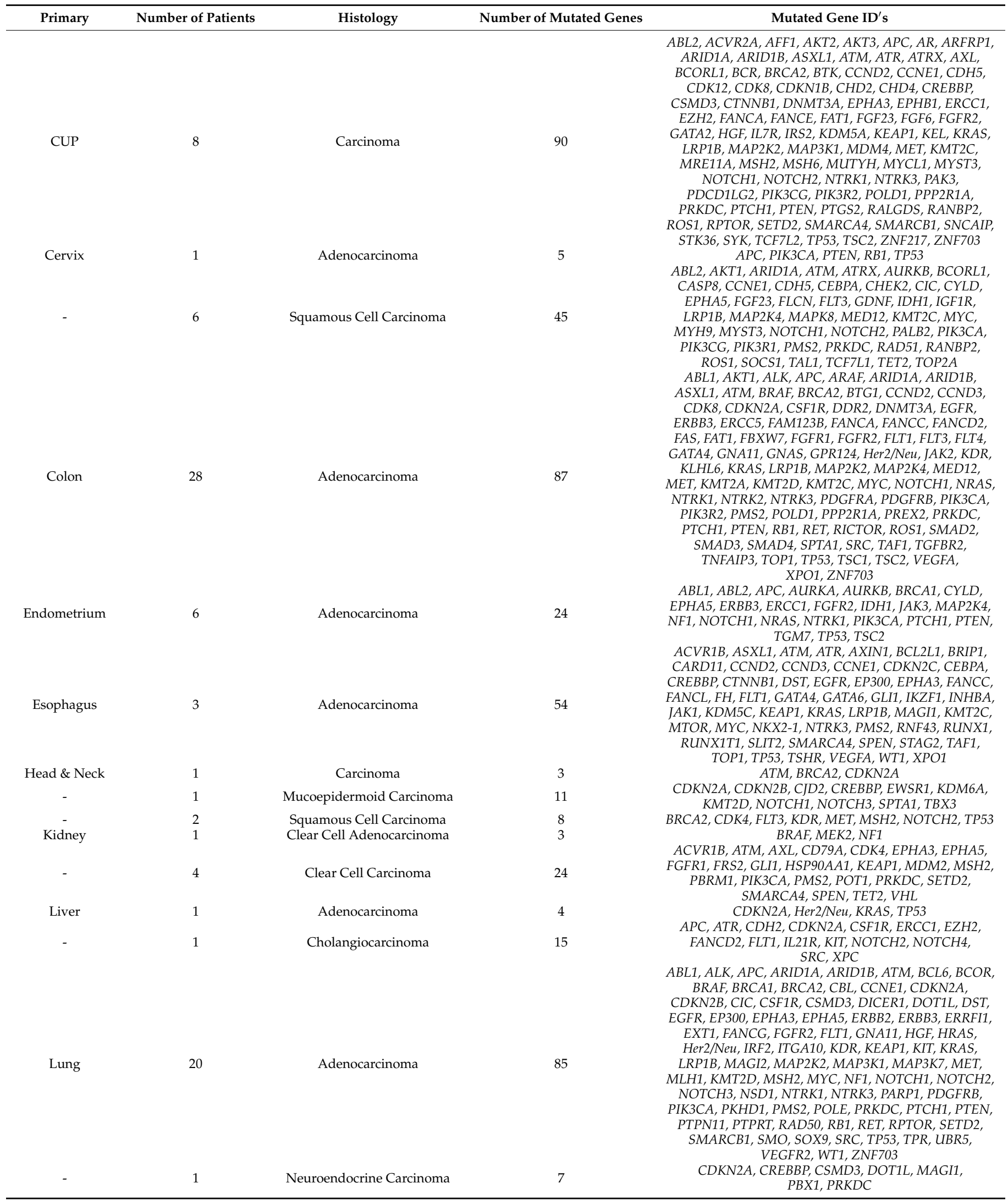


Table 1. Cont.

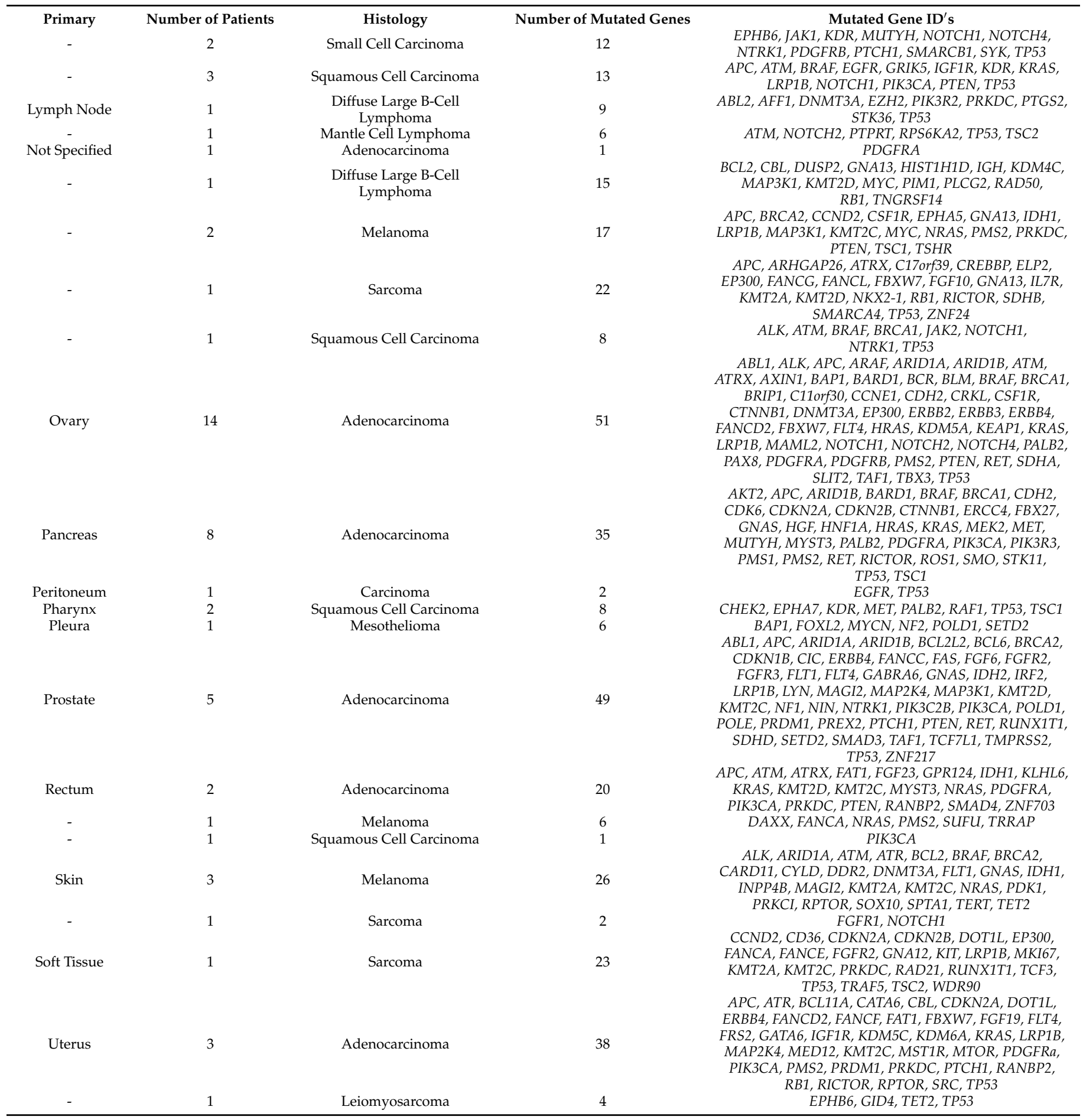

Combined patient gene mutation profiles showing genes mutated in at least one patient. Profiles obtained with NGS using Precipio-421-NGS, Caris-Molecular Intelligence, and Foundation One platforms. Total patients: 171.

Of the 171 phase I cancer patients with mutations, adenocarcinoma is the most common $(n=111)$, followed by squamous cell carcinoma $(n=17)$, CUPS $(n=11)$ and melanoma $(n=6)$. We determined the average number of unique mutations per patient for adenocarcinoma $(n=7)$, squamous cell carcinoma $(n=6)$, CUPS $(n=10)$, and melanoma $(n=8)$. In our patient cohort, mutation frequency among the drivers of malignancy, TP53 had the highest frequency $(92, \sim 54 \%)$, followed by APC (47, 27\%), KRAS (36, 27\%), PIK3CA (31, $\sim 18 \%), \operatorname{ATM}(25, \sim 15 \%), \operatorname{NOTCH} 1(23, \sim 7 \%), \operatorname{PTEN}(22, \sim 13 \%)$, BRCA2 $(20,12 \%)$, BRAF 
(20, 12\%), KMT2D (19, 11\%), LRP1B (18, 11\%) and CDKN2A (16, 9\%) (Figure 1A). Our study identified gene mutations unique to primary and metastatic sites that track with common mutations. Individual patient data was further screened for accurate and unique identification of primary or metastatic biopsy sites resulting in 145 patient samples. The frequency of individual gene mutations in primary and metastatic samples of 145 patients across all tumor types was estimated. Some of the gene mutations were found to be prevalent with significance to both primary and metastatic tissues, while others occurred with higher frequency in primary or metastatic sites (Figure 1B,C).

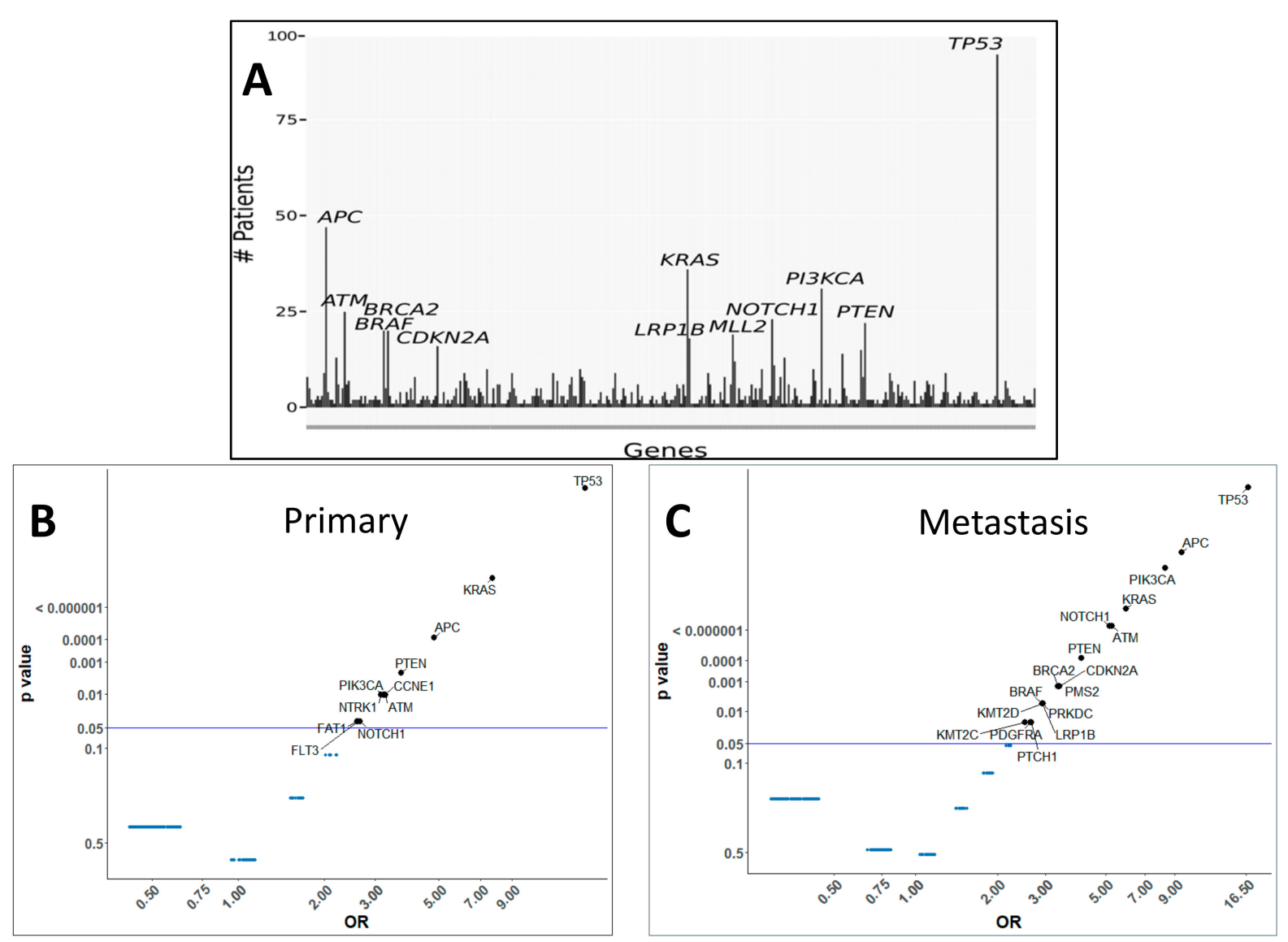

Figure 1. The mutation frequency of the common drivers of malignancy. (A) Most frequently mutated genes for 171 advanced cancer patients in study. Top 12 mutated genes labeled with gene name. Plot showing representation of gene mutations with significance ( $p$-values $<0.05$ ) across $(\mathbf{B})$ primary samples and $(\mathbf{C})$ metastatic samples. Y-axis is $p$-value and $\mathrm{X}$-axis is the odds ratio. Significant genes are labeled and highlighted.

The relative frequency of TP53 mutations amongst other genes was 0.54 in primary $\left(p\right.$ value $\left.(\mathrm{val})=7.9 \times 10^{-28}\right)$ and $0.45\left(p\right.$ val $\left.=1.42 \times 10^{-41}\right)$ in metastatic tissue samples (Figure 2) respectively. TP53 was the most frequent gene in both primary and metastatic sites followed by KRAS, APC, PTEN, PIK3CA, ATM, and NOTCH1. In addition, Figure 2 shows that metastatic sites carry several new mutations with higher frequency (KMT2D, $B R A F, B R C A 2, K M T 2 C, P R K D C$ ) along with the top driver mutations found in primary sites. There is a combination of cell signaling genes, DNA damage repair, and histone methyltransferase genes that are common to primary and metastatic sites and some unique to metastatic sites. The enrichment of multiple DNA damage repair proteins in metastatic sites suggest potential for investigating the safety and efficacy of PARP inhibitors therapy in a 'basket' trial. It is well known that there is an interplay between epigenetic pathways and TP53 mutations. We see a statistically significant enrichment of mutations of the KMT2 family of histone modifying genes. These proteins are part of multimeric complexes that bind with other proteins to target enhancers across the genome that impact complex 
gene regulation. Their mutated frequencies in tumors have been reported [18] and are critical co-occurring mutations which opens possibilities for pharmacologic intervention that target cofactors in gene regulation complexes.

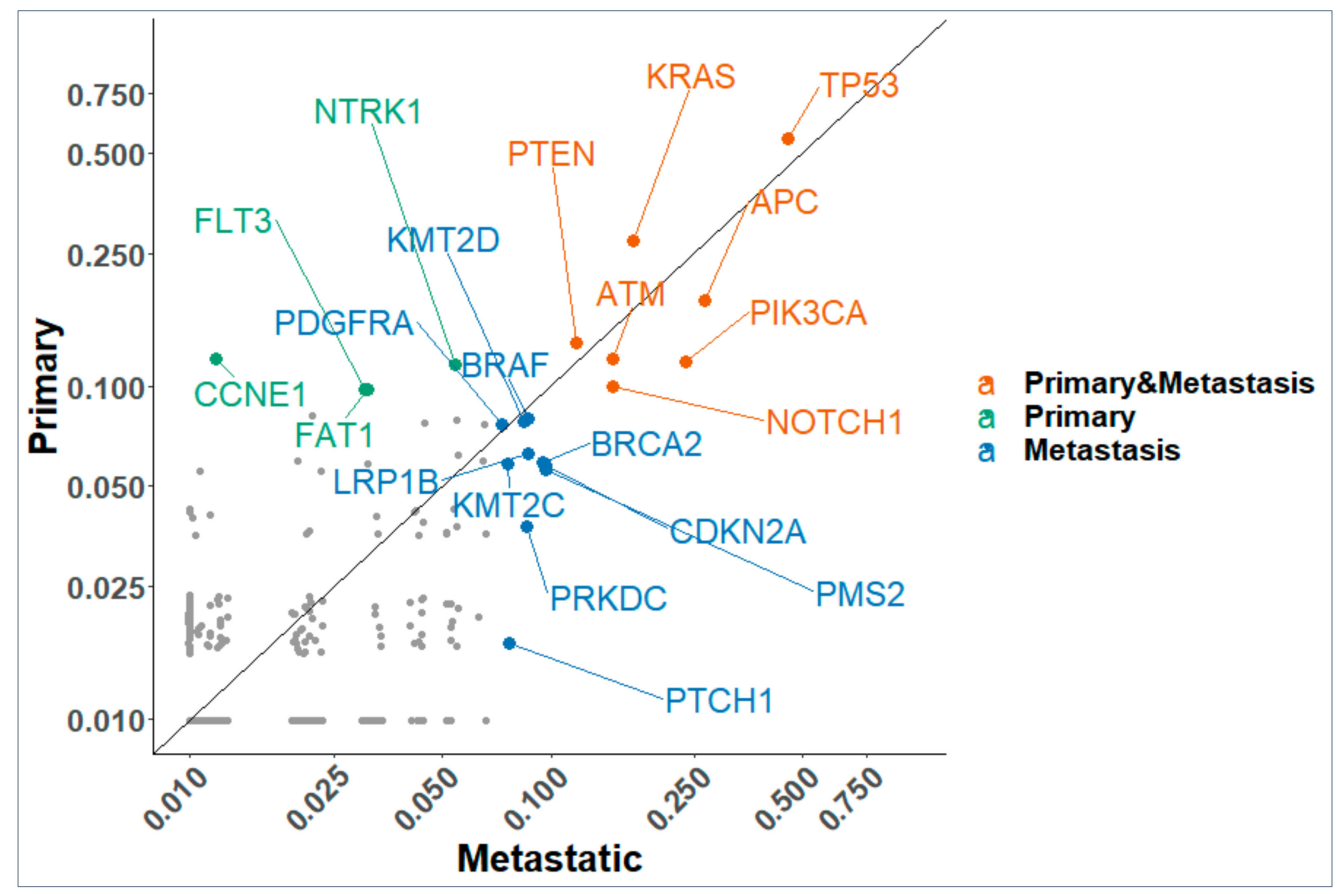

Figure 2. Scatter plot of frequencies of gene mutations in primary and metastatic samples. Genes that are enriched in primary, metastatic or both samples with $p$ value $<0.05$ are labeled.

\subsection{Gene Mutation Networks in Lung and Colon Cancer}

The system-wide profiling of pathogenic mutations in human cancer produces lists of genes that can be evaluated for their collective functions in order to garner new knowledge. Well annotated lists of genes can be input for enrichment into existing lists from prior knowledge. This methodology was applied to the overrepresented gene mutations across all primary and metastatic sites in lung and colon cancer cohorts of patients. Lung cancer patients were divided into adenocarcinoma, squamous cell carcinoma, and small cell lung cancer for this analysis. Figure 3A shows the site of biopsy for each subtype of lung cancer with their mutational profile, frequency and significant enrichments of genes. Node sizes reflect the abundance of a particular gene mutation. Although metastatic tumors harbor an increased number of genetic alterations, some of the alterations found in the primary tumor are preserved. Cytoscape analysis demonstrate that TP53 mutations are a major central node with combined Frequency $(\mathrm{F})$ of 0.8 in primary and metastatic tumors, dictating the 3 subtypes of lung cancer pathogenesis. Statistical analysis shows TP53 enrichment with significance in both primary $(p$ value $=0.01)$ and metastatic sites but a higher frequency and significance in metastatic patients ( $p$ value $=5.75 \times 10^{-13}$ ) (Figure 3B). For adenocarcinoma of the lung, the TP53 oncogenic program impacts genetic aberrancies in all the hallmarks of cancer which includes alterations in the cell cycle, DNA repair, epigenetic regulation, growth factor receptor RAS-MAPK signaling, GPCR signaling, apoptosis, and stemness pathways. We evaluated the top mutated genes (Figure 3A) for significant enrichment of Kegg pathways, Figure $3 \mathrm{C}$ shows the altered signaling pathways based on the top mutations and many of the pathways known for alteration in TP53 mutated tumors are prevalent. For squamous cell carcinoma of the lung, the mutational burden is less than that for adenocarcinoma, however, TP53 mutations are a driver and associate with several known oncogenes (KRAS, BRAF, and PI3KCA). For small cell lung cancer, TP53 mutations associate with angiogenic factors (KDR, PDGFRB, EPHB6), stem cell markers (NOTCH1, 4 and PTCH1), and a novel NTRK1 mutation. 

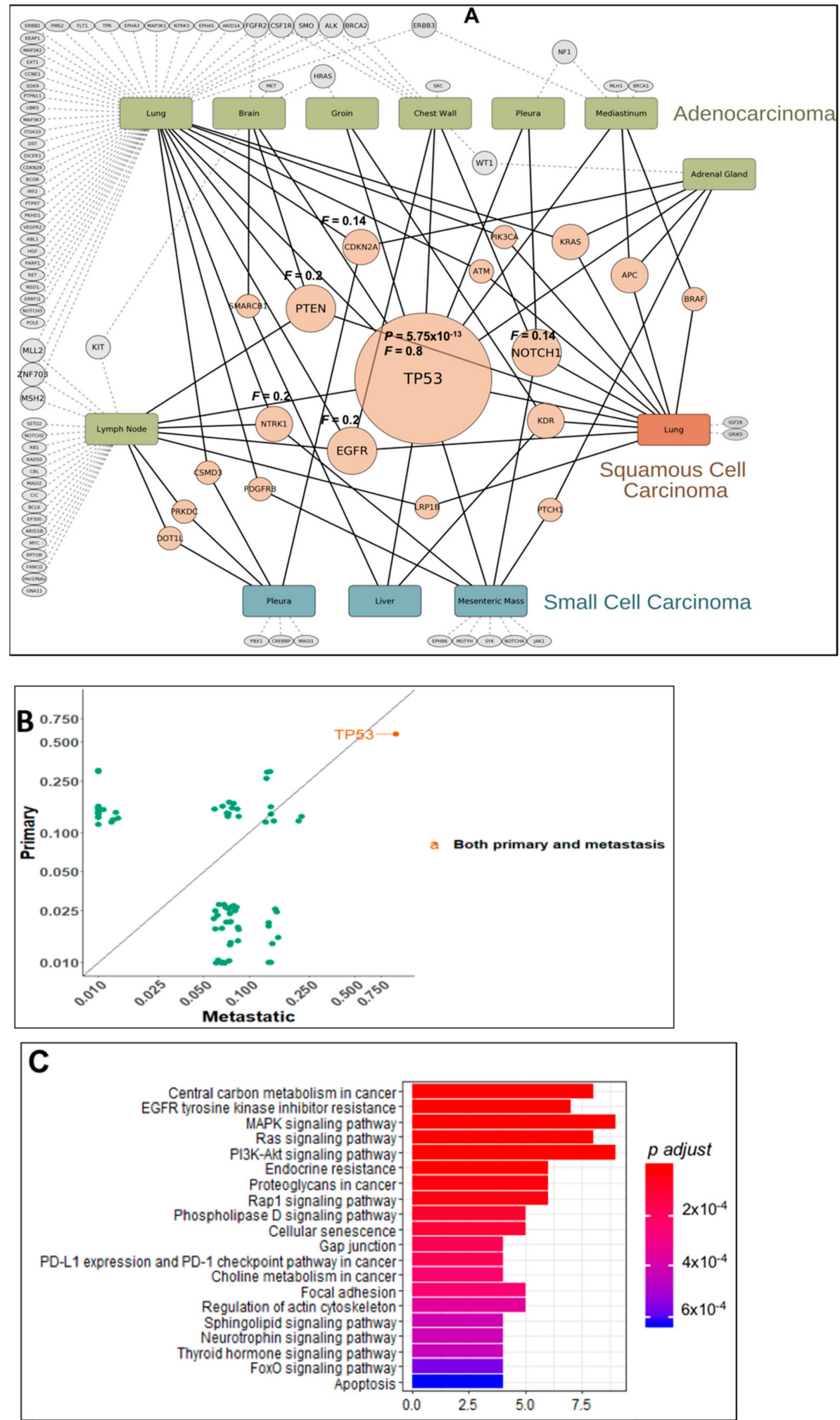

Figure 3. (A) Map of mutation frequencies in lung cancer patients. "Gene" node sizes positively correlate with total mutation frequency $(\mathrm{F})$ of the gene among all primary/metastatic sites. Rectangular nodes: Primary/metastatic sites colored by histology type. Pink-colored gene nodes: Genes mutated in multiple primary/histology types. Gray-colored genes nodes: Mutated genes unique to a particular site. (B) Plot of relative frequency of gene mutations in primary and metastatic and gene enriched are highlighted. (C) Signaling pathways altered by significant gene mutation. Genes with significant mutations were analyzed for enrichment of Kegg pathways. Pathways with adjusted $p$ value $<0.05$ were selected. The plot shows the significant pathways with bar height as gene counts. 
For colon cancer, statistical analysis showed the primary site mutations with combined frequency in primary and metastatic sites of 0.8 in APC and TP53 that are the major drivers followed by KRAS $(F=0.4)$, PIK3CA $(F=0.32), B R A F(F=0.2)$ and SMAD4 $(F=0.17)$ pathogenic mutations respectively (Figure 4A). TP53 mutations are higher in metastatic sites but new co-mutations become prevalent in metastatic colon tumor. Statistical analysis shows TP53 enrichment with significance occurs in both primary $\left(p\right.$ value $\left.=4.2 \times 10^{-9}\right)$ and metastatic sites $\left(p\right.$ value $\left.=3.5 \times 10^{-5}\right)$. In a study [19] that evaluated p53 mutations in primary and metastatic tumors and CTCs from colorectal cancer (CRC) patients reported identical TP53 mutations in both sites. However, in another study TP53 mutations were shown to enrich to metastatic sites [16]. Of the metastatic sites, lung cancer shows the most diverse profile compared to colon. All other metastatic sites have only a few unique mutations (Figure 4A). As known from previous studies, the top 4 driver mutations in our colon cancer cohort with statistical significance are TP53, KRAS, and APC with PIK3CA (Figure $4 \mathrm{~B}$ ) mutations that are more prevalent in metastatic sites as these are late occurring mutations in CRC. Figure 4C shows signal transduction pathways affected by significant mutations in colon cancer (Figure 4A). Signaling pathway changes known in TP53 mutated tumors are overrepresented in the list of pathways. A RAS wild type colon cancer patient with HER2+ by CISH and IHC 3+ had 2 pathogenic TP53 mutations affecting both alleles indicating a rare and novel event. Similar profiles have also been generated for breast cancer (ER/PR, HER2/Neu, TNBC, TPBC), ovarian cancer, and CUPS. Data provides information for potential targeted functional studies.

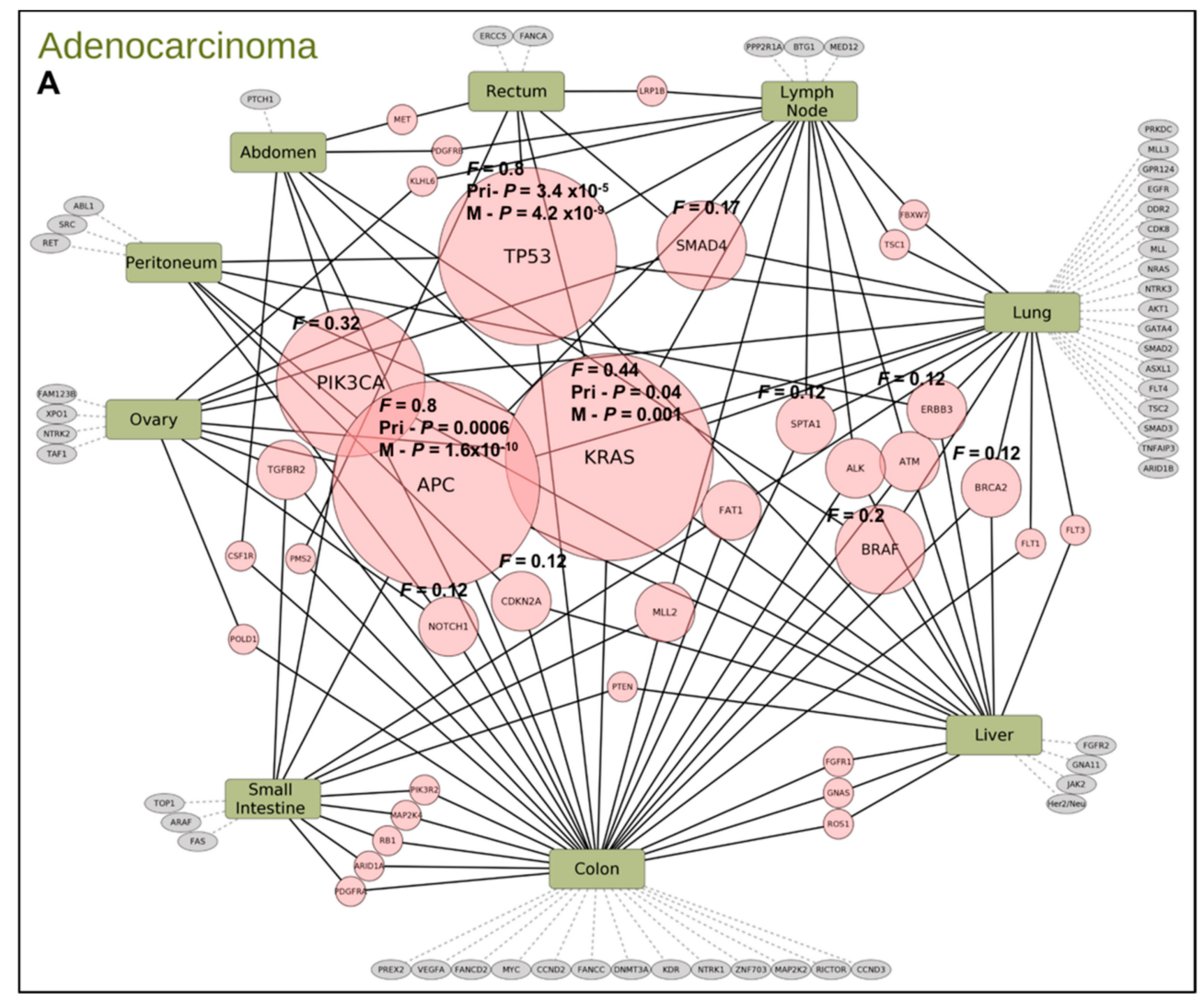

Figure 4. Cont. 

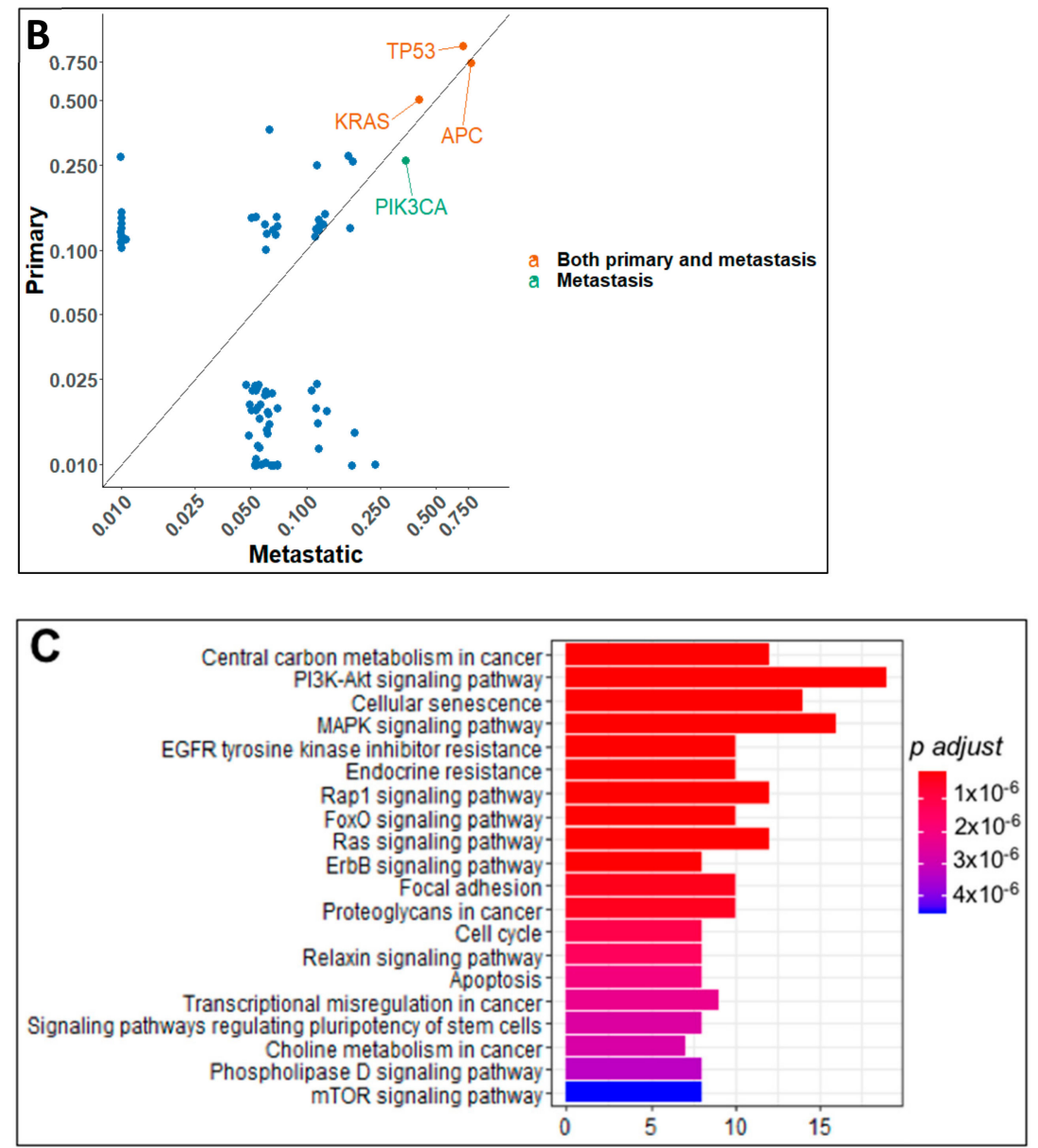

Figure 4. (A) Map of mutation frequencies (F) in colon cancer patients with adenocarcinoma histology type. "Gene" node sizes positively correlate with gene mutation frequency. Pink-colored gene nodes: genes mutated in multiple primary/metastatic sites. Gray-colored gene nodes: mutated genes unique to the particular primary/metastatic site. (B) Plot of relative frequency of gene mutations in primary and metastatic and gene enriched are highlighted. (C) Signaling pathways altered by significant gene mutation. Genes with significant mutations were analyzed for enrichment of Kegg pathways. Pathways with adjusted $p$ value $<0.05$ were selected. The bar plot shows the significant pathways with bar height as gene counts.

\subsection{Distribution of TP53 Mutations among Tumor Types}

In our cohort of patients, TP53 is mutated more often in lung $(80 \%)$, colon $=$ pancreas (75\%), CUPS (63\%), and breast (41\%) cancers. No TP53 mutations were detected in the rectum, anus, appendix and melanoma (Table 2). The type of TP53 mutation is variable with most affecting the central DNA-binding core domain and to a lesser degree the Cterminal domain that down-regulates DNA binding to the central domain and the acidic $\mathrm{N}$-terminus transcription-activation domain. We hypothesized that distinct TP53 mutations may track with unique co-mutations that orchestrate distinct transcriptional programs and signaling pathways.

We evaluated TP53 in the context of other oncogenes that track with it at metastatic sites in each tumor site (Figure 5A). Some TP53 mutations are conserved in both primary and metastatic sites, while new mutations are acquired in metastatic samples. Loss of p53 function via missense or truncating mutations occurs in many human tumors. Over $75 \%$ of TP53 mutations result in the loss of wild-type function which exerts dominant-negative regulatory effects over co-expressed wild-type p53. Mutant p53 may be oncogenic in ways not related to those associated with wild type p53 functions [20,21] which include cell invasion, migration, scattering, survival, proliferation, angiogenesis, stem cell expansion, 
and tissue remodeling. We characterized individual TP53 mutations in each tumor type to better understand the diversity of mutant sites (Figure 5B).

Table 2. Distribution of TP53 mutations among tumor types.

\begin{tabular}{ccccc}
\hline Primary & Histology & Number of Patients & $\begin{array}{c}\text { Number of Patients } \\
\text { with mutTP53 }\end{array}$ & $\begin{array}{c}\text { Fraction Patients with } \\
\text { mutTP53 }\end{array}$ \\
\hline Breast & Adenocarcinoma & 17 & 7 & 0.41 \\
Colon & Adenocarcinoma & 28 & 21 & 0.75 \\
CUP & Carcinoma & 8 & 5 & 0.63 \\
Endometrium & Adenocarcinoma & 6 & 2 & 0.33 \\
Lung & Adenocarcinoma & 20 & 16 & 0.80 \\
Ovary & Adenocarcinoma & 14 & 7 & 0.50 \\
Pancreas & Adenocarcinoma & 8 & 6 & 0.75 \\
\hline
\end{tabular}

Fraction of patients with mutated TP53 by primary site and histology.
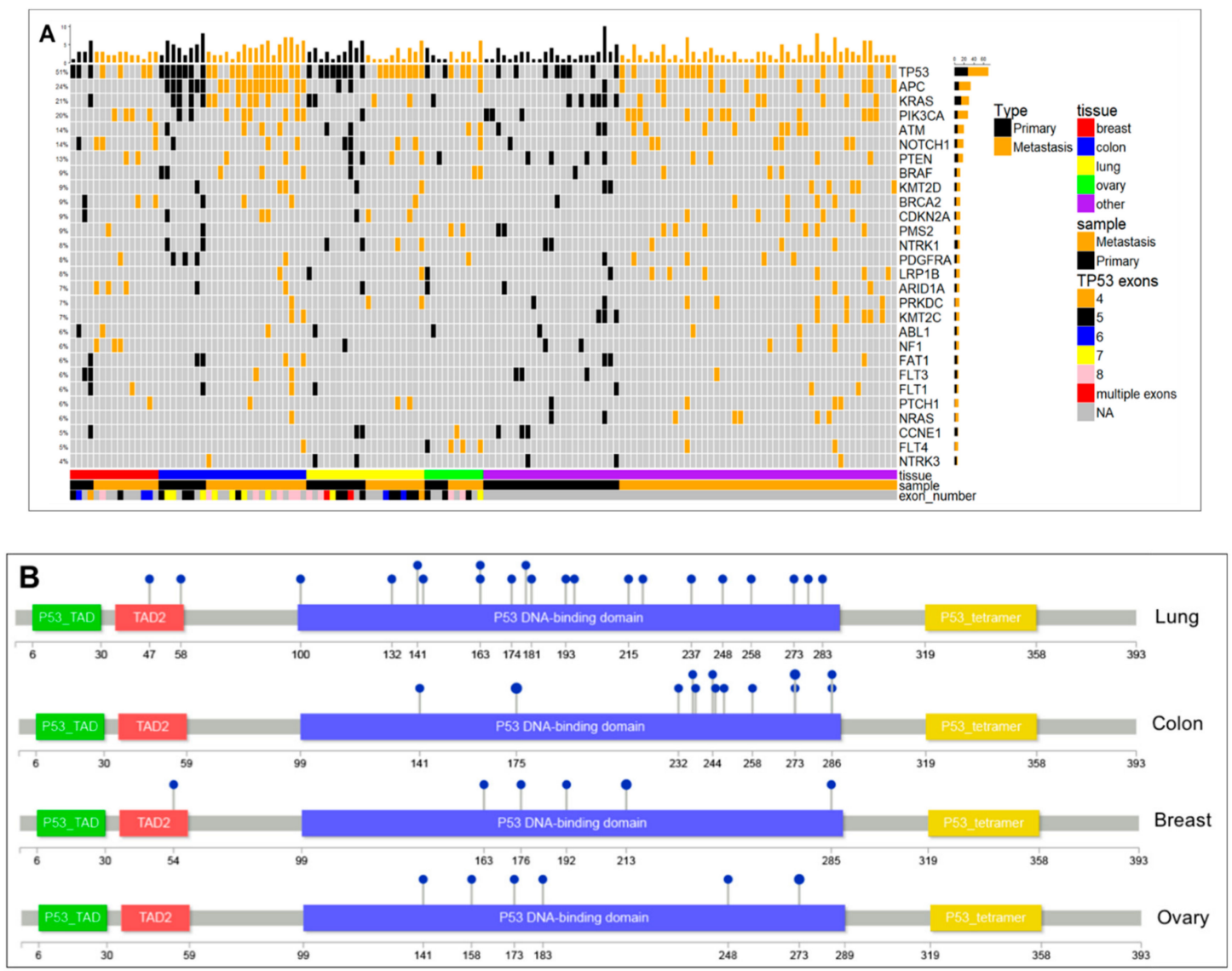

Figure 5. (A) Mutational profile of all patients from all tumor types. The figure shows frequency of mutations and differences in primary and metastatic tissue for different tumor types. (B) Schematic diagram of TP53 gene and its site-specific mutations in lung, colon, breast, and ovarian tumor tissues.

In lung cancer, TP53 mutations are spread across the DNA binding domain (DBD). In the colon, TP53 mutations are clustered toward the c-terminal end of the DBD which directly interacts with DNA (Figure S1). For breast and ovarian cancer, TP53 mutations are clustered more in the middle of the DBD (Figure 5B). It is known that small changes in p53 protein do not necessarily preclude expression with some wild-type activities. Analyses of TP53 mutation-site clustering indicate that DNA-binding activity direct versus indirect, may alter the target gene transcription affecting p53-dependent signaling pathways. 
TP53 mutations are divided into 2 categories: structural mutants, where protein folding is altered and DNA-contact mutants, where changes in critical amino acids affect DNA binding. Well characterized structural mutants such as $\mathrm{R} 175 \mathrm{H}$ are highly unfolded under physiological conditions. Contact mutants such as R248Q exhibit decreased structural stability compared to wild type p53 [22]. We cataloged common and unique TP53 mutations for lung cancer (Table 3, Figure 5B) and colon cancer (Table 4, Figure 5B) with respect to aberrations documented from functional studies. In lung adenocarcinoma, mutations are observed in exon $4(n=3)$, exon $5(n=8)$, exon $6(n=4)$, exon $7(n=6)$, and exon $8(n=3)$. In colon adenocarcinoma, mutations occur in exon $5(n=2)$, exon $6(n=1)$, exon $7(n=8)$ and exon $8(n=6)$. Mutations in exon 4 affect transactivation while mutations in exon 5 , 6 and 7 are buried within the p53 structure and affect DNA binding. Mutation in exon 5 (lung cancer) and two mutations in exon 7 (colon cancer), affect zinc binding while exon 8 mutations partially expose DNA binding.

Table 3. Catalog of common and unique TP53 mutations for lung cancer.

\begin{tabular}{|c|c|c|c|c|}
\hline Protein Mutation & Exon/Intron & Residue Function & Domain Function & Structural Motif \\
\hline P47S & 4 exon & na & Transactivation & $\begin{array}{c}\text { N-terminal } \\
\text { Transactivation }\end{array}$ \\
\hline P58R & 4 exon & na & na & N-term \\
\hline Q100* & 4 exon & na & na & N-term \\
\hline K132M & 5 exon & Buried & DNA binding & $\mathrm{L} 1 / \mathrm{S} / \mathrm{H} 2$ \\
\hline C141Y & 5 exon & Buried & DNA binding & NDBL/beta-sheets \\
\hline V143M & 5 exon & Buried & DNA binding & NDBL/beta-sheets \\
\hline Y163N & 5 exon & Buried & DNA binding & NDBL/beta-sheets \\
\hline Y163C & 5 exon & Buried & DNA binding & NDBL/beta-sheets \\
\hline R174W & 5 exon & Partially exposed & DNA binding & $\mathrm{L} 2 / \mathrm{L} 3$ \\
\hline H179L & 5 exon & Zn binding & DNA bindin & L2/L3 \\
\hline R181P & 5 exon & Exposed & DNA binding & L2/L3 \\
\hline H193R & 6 exon & Buried & DNA binding & L2/L3 \\
\hline R196G & 6 exon & Buried & DNA binding & NDBL/beta-sheets \\
\hline S215I & 6 exon & Buried & DNA binding & NDBL/beta-sheets \\
\hline Y220C & 6 exon & Buried & DNA binding & NDBL/beta-sheets \\
\hline M237I & 7 exon & Buried & DNA binding & L2/L3 \\
\hline M237I & 7 exon & Buried & DNA binding & L2/L3 \\
\hline M237I & 7 exon & Buried & DNA binding & L2/L3 \\
\hline R248W & 7 exon & DNA binding & DNA binding & L2/L3 \\
\hline R248W & 7 exon & DNA binding & DNA binding & L2/L3 \\
\hline E258G & 7 exon & Buried & DNA binding & NDBL/beta-sheets \\
\hline R273L & 8 exon & DNA binding & DNA binding & $\mathrm{L} 1 / \mathrm{S} / \mathrm{H} 2$ \\
\hline P278A & 8 exon & Buried & DNA binding & $\mathrm{L} 1 / \mathrm{S} / \mathrm{H} 2$ \\
\hline $\mathrm{R} 283 \mathrm{P}$ & 8 exon & DNA binding & DNA binding & $\mathrm{L} 1 / \mathrm{S} / \mathrm{H} 2$ \\
\hline
\end{tabular}

IARC TP53 Database search results for TP53 mutations in lung cancer patients. Most mutations are in exons 4, 5, 6, 7, and 8 located in the DNA binding domain. * represents unknown.

Tetramers of p53 bind to DNA targets through two decameric half-sites separated by a variable nucleotide spacer. The spacer length (contiguous versus non-contiguous) determines affinity of protein-protein and protein-DNA interactions [20]. A crystal structure of p53 bound to DNA (Watson-Crick and Hoogsteen) was utilized to map various p53 DNA-binding domain mutations detected in our cohort of patients (Figure S1). For example, R248W (lung cancer) or R248Q (colon cancer) interfere with DNA binding affinity. H179L (lung cancer) and C238S (colon cancer) disrupt zinc binding and stabilization of a loop-sheet-helix motif necessary for protein-protein interactions. TP53 mutations away from DNA and protein-protein interaction sites enhance structural disruption of the p53 protein that dysregulate affinity of binding to DNA targets, thus potentially driving different oncogenic signaling pathways. In addition, TP53 mutations may be truncal or acquired at metastatic sites. 
Table 4. Catalog of common and unique TP53 mutations for colon cancer.

\begin{tabular}{|c|c|c|c|c|}
\hline Protein Mutation & Exon/Intron & Residue Function & Domain Function & Structural Motif \\
\hline C141Y & 5 exon & Buried & DNA binding & NDBL/beta-sheets \\
\hline $\mathrm{R} 175 \mathrm{H}$ & 5 exon & Buried & DNA binding & L2/L3 \\
\hline R213L & 6 exon & Buried & DNA binding & NDBL/beta-sheets \\
\hline $\mathrm{I} 232 \mathrm{~S}$ & 7 exon & Buried & DNA binding & NDBL/beta-sheets \\
\hline M237K & 7 exon & Buried & DNA binding & L2/L3 \\
\hline C238S & 7 exon & Zn binding & DNA binding & L2/L3 \\
\hline $\mathrm{C} 238 \mathrm{~S}$ & 7 exon & Zn binding & DNA binding & $\mathrm{L} 2 / \mathrm{L} 3$ \\
\hline G244S & 7 exon & Exposed & DNA binding & L2/L3 \\
\hline G245S & 7 exon & Buried & DNA binding & $\mathrm{L} 2 / \mathrm{L} 3$ \\
\hline R248Q & 7 exon & DNA binding & DNA binding & L2/L3 \\
\hline $\mathrm{R} 248 \mathrm{Q}$ & 7 exon & DNA binding & DNA binding & $\mathrm{L} 2 / \mathrm{L} 3$ \\
\hline $\mathrm{R} 273 \mathrm{C}$ & 8 exon & DNA binding & DNA binding & $\mathrm{L} 1 / \mathrm{S} / \mathrm{H} 2$ \\
\hline $\mathrm{R} 273 \mathrm{H}$ & 8 exon & DNA binding & DNA binding & $\mathrm{L} 1 / \mathrm{S} / \mathrm{H} 2$ \\
\hline E286K & 8 exon & Partially exposed & DNA binding & $\mathrm{L} 1 / \mathrm{S} / \mathrm{H} 2$ \\
\hline E286K & 8 exon & Partially exposed & DNA binding & $\mathrm{L} 1 / \mathrm{S} / \mathrm{H} 2$ \\
\hline E286G & 8 exon & Partially exposed & DNA binding & $\mathrm{L} 1 / \mathrm{S} / \mathrm{H} 2$ \\
\hline E286G & 8 exon & Partially exposed & DNA binding & $\mathrm{L} 1 / \mathrm{S} / \mathrm{H} 2$ \\
\hline
\end{tabular}

IARC TP53 Database search results for TP53 mutations in colon cancer patients. Most mutations are in exon 5, 7, and 8 located in the DNA binding domain.

Protein-protein interaction data from Stringdb show that the p53 protein strongly interacts with multiple proteins (Figure S2A). Different mutated TP53 sites may affect binding and interactions and in turn dysregulate p53-dependent signaling pathways. We searched for protein-interaction networks for top key mutated genes in lung and colon metastatic samples (Figure S2B,C) which showed two different networks for colon and lung with TP53 as one of the central nodes. Some of the nodes are preserved between the two tissue types, but additional nodes produce new interactions and possible changes to integrated signaling mechanisms.

\subsection{Pre- and Post-Targeted Therapy Response}

Finally, we report on the molecular profiles pre- and/or post-treatment of 10 advanced cancer patients undergoing targeted (small molecule and monoclonal antibodies) and immune checkpoint therapy to highlight unique pathways with insights to molecular responses (Table 5). The most intriguing is the effect of targeted therapies on epistasis, a phenomenon where the effect of one gene depends upon the genetic background or presence of other modifier genes. Moreover, in contrast to individual mutations, combinations of epistatic mutations may have unique effects including unexpected phenotypes and inherent resistance to single agent therapies.

Case \#9 is of a patient with an EML4-ALK inversion non-small cell adenocarcinoma of the lung treated with crizotinib and highlights persistence of the target EML4-ALK on initial chronic crizotinib with a complete remission but then slow relapse on crizotinib without a resistant mutation. The patient enrolled on a phase Ib study of crizotinib plus an HSP90 inhibitor [23] and had a near complete remission, however, a persistent pleural effusion led to withdrawal from the study. Cell and molecular analysis of the pleural fluid was positive for adenocarcinoma but FISH confirmed the loss of EML4-ALK inversion, respectively. Moreover, NGS showed the tumor had acquired several novel gene mutations that may be targetable (Figure 6). The potential therapies suggested include CDK46 inhibitor or immune checkpoint therapy (Table 5). 
Table 5. Mutational signatures and pathway analysis of pre- and/or post- targeted therapies individualized in advanced cancer patients entering phase I therapeutic trials.

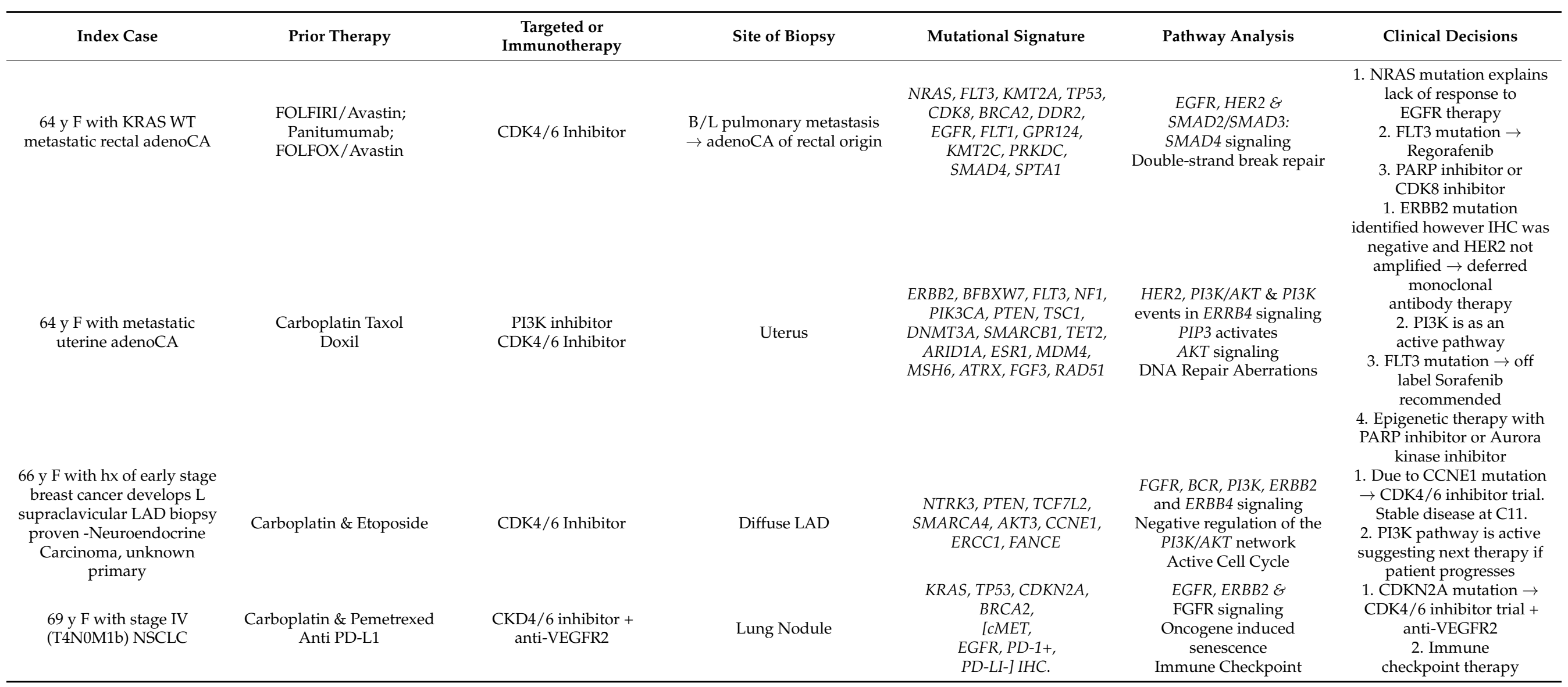


Table 5. Cont.

\begin{tabular}{|c|c|c|c|c|c|c|}
\hline Index Case & Prior Therapy & $\begin{array}{c}\text { Targeted or } \\
\text { Immunotherapy }\end{array}$ & Site of Biopsy & Mutational Signature & Pathway Analysis & Clinical Decisions \\
\hline $\begin{array}{l}52 \text { y F with metastatic } \\
\text { EML4-ALK NSCLC }\end{array}$ & $\begin{array}{c}\text { Crizotinib; Crizotinib + } \\
\text { HSP90 Inhibitor } \\
\text { ChemoRT to the R hilum }\end{array}$ & Crizotinib & L supraclavicular node & $\begin{array}{c}\text { Persistent } A L K+\text { by IHC \& } \\
\text { FISH. No } A L K \text { mutation } \\
\text { within } E M L 4-A L K \\
\text { translocation; } P D-1 \text { and } \\
P D-L 1 \text { negative, BRCA2, } \\
\text { FGFR1, NOTCH1 }\end{array}$ & $\begin{array}{l}\text { FGFR and FGFR1 ligand } \\
\text { binding, activation \& } \\
\text { signaling } \\
\text { Receptor-ligand binding } \\
\text { initiates second proteolytic } \\
\text { cleavage of } \\
\text { NOTCH receptor } \\
\text { Double-strand break repair }\end{array}$ & $\begin{array}{l}\text { 1. Continue Crizotinib as } \\
\text { there is no new mutation } \\
\text { acquired in the } \\
\text { ALK domain. } \\
\text { 2. Investigate FGFR1 } \\
\text { mutation as an active driver } \\
\text { of potential clinical } \\
\text { relevance and } \\
\text { laboratory focus. }\end{array}$ \\
\hline $\begin{array}{l}60 \text { y M with metastatic } \\
\text { squamous cell carcinoma of } \\
\text { the lung }\end{array}$ & ChemoRT & Anti-PDL1 antibody & Lung & $\begin{array}{c}\text { PD-1+, APC } \\
\text { PTCH1, }-M E T ; T L 3 \\
\text { TOPO1; TUBB3 }\end{array}$ & $\begin{array}{c}\text { Beta-catenin } \\
\text { phosphorylation } \\
\text { cascadeTruncated APC } \\
\text { mutants \& deletions of } \\
\text { AMER1 destabilize the } \\
\text { destruction complex }\end{array}$ & $\begin{array}{l}\text { 1. AMER1 mutation, a } \\
\text { tumor suppressor gene } \\
\text { resulting over-activity of the } \\
\text { Wnt signaling pathway. } \\
\text { 2. Immune checkpoint }\end{array}$ \\
\hline $\begin{array}{l}61 \text { y F with metastatic lung } \\
\text { adenocarcinoma with EGFR } \\
\text { exon } 19 \text { deletion and HER2 } \\
\text { amplification by CISH/IHC }\end{array}$ & $\begin{array}{l}\text { Tarceva } \\
\text { Afatinib }\end{array}$ & $\begin{array}{c}\text { Monoclonal antibody } \\
\text { to HER2 }\end{array}$ & $\begin{array}{l}\text { Lung } \\
\text { Pleural fluid }\end{array}$ & $\begin{array}{c}\text { Pre-targeted therapy: EGFR } \\
\text { Exon } 19 \text { Deletion } \\
\text { (L747_S752 del) } \\
\text { ERBB2 amplification } \\
\text { (FISH/CISH 6.4) } \\
\text { PIK3CA } \\
\text { TOPO2A } \\
\text { TP53 } \\
\text { KEL intron } 3 \\
\text { Rearrangement } \\
\text { Post-targeted therapy: } \\
\text { Loss of ERBB2 amplification } \\
\text { by FISH and IHC } \\
\text { EGFR Exon } 19 \text { deletion } \\
\text { Loss of PIK3CA } \\
\text { FLT3 (V194M) } \\
\text { TP53 } \\
\text { TOPO2A } \\
\text { PD-1 negative } \\
\text { PD-L1 negative }\end{array}$ & $\begin{array}{c}\text { EGFR, ERBB2, FGFR \& } \\
\text { PI3K Signaling } \\
\text { PI3K/AKT activation } \\
\text { G1/S DNA } \\
\text { Damage Checkpoints }\end{array}$ & $\begin{array}{l}\text { 1.Tumor evolution across } \\
\text { therapy-Loss of target } \\
\text { 2. Network analysis reveals } \\
\text { alternate activated } \\
\text { pathways- PI3K and } \\
\text { DNA repair }\end{array}$ \\
\hline
\end{tabular}


Table 5. Cont.

\begin{tabular}{|c|c|c|c|c|c|c|}
\hline Index Case & Prior Therapy & $\begin{array}{c}\text { Targeted or } \\
\text { Immunotherapy }\end{array}$ & Site of Biopsy & Mutational Signature & Pathway Analysis & Clinical Decisions \\
\hline $\begin{array}{l}60 \mathrm{y} F \text { with metastatic } \\
\text { adenocarcinoma of the lung } \\
\text { with EGFR INDEL } \\
\text { (exon 19) mutation }\end{array}$ & $\begin{array}{l}\text { Carboplatin } \\
\text { Pemetrexed } \\
\text { Bevacizumab }\end{array}$ & $\begin{array}{l}\text { Tarceva } \\
\text { Afatinib }\end{array}$ & Lung nodule & $\begin{array}{c}\text { Pre-targeted therapy: } \\
\text { EGFR (INDEL) exon } 19 \\
\text { TP53 } \\
\text { CSF-1R } \\
\text { PMS } 2 \\
\text { ARID1A } \\
\text { PKHD1 } \\
\text { PTPRT } \\
\text { TPR } \\
\text { Post-targeted therapy: } \\
\text { EGFR (INDEL) exon19 } \\
\text { EGFR (T790M) } \\
\text { TP53 } \\
\text { CSF-1R } \\
\text { PD-1 positive } \\
\text { PD-L1 negative } \\
c-M E T \text { positive } \\
\text { M237I }\end{array}$ & $\begin{array}{l}\mathrm{p}-53 \text { dependent } \mathrm{G} 1 / \mathrm{S} \text { DNA } \\
\text { Damage Checkpoint } \\
E G F R \& \text { ERBB2 signaling }\end{array}$ & $\begin{array}{l}\text { 1. Recommend } \\
\text { AZD9291 } \pm \text { Mab to PD-L1 } \\
\text { or Mab to MET } \\
\text { 2. Consider MEK inhibitor3. } \\
\text { Consider Osimertinib }\end{array}$ \\
\hline $\begin{array}{l}52 \text { y F with Stage IV } \\
\text { EML4-ALK NSCLC }\end{array}$ & Crizotinib & HSP90 inhibitor + crizotinib & $\begin{array}{l}\text { Persistent R pleural } \\
\text { effusion } \rightarrow \text { moderately } \\
\text { differentiated } \\
\text { adenocarcinoma }\end{array}$ & $\begin{array}{c}\text { Loss of EML4-ALK by } \\
\text { FISH, CDKN2A, } \\
\text { CSMD3, MAGI1, CREBBP, } \\
\text { DOT1L, PBX1, PRKDC }\end{array}$ & $\begin{array}{l}\text { Pre-NOTCH Transcription } \\
\text { and Translation } \\
\text { Double Strand Break Repair } \\
\text { Notch-HLH transcription } \\
\text { pathway }\end{array}$ & $\begin{array}{l}\text { 1. Loss of ALK (inversion) } \\
\text { 2. Alternate activated } \\
\text { pathways for future } \\
\text { targeting with epigenetic } \\
\text { therapy, DNA repair } \\
\text { inhibitors and cell } \\
\text { cycle inhibitors } \\
\text { 3. Anti-PD-1 Mab }\end{array}$ \\
\hline $\begin{array}{l}\text { 10. } 74 \text { y F with stage IVA } \\
\text { triple hit DLBCL }\end{array}$ & R-EPOCH X 6 cycles & $\begin{array}{l}\text { IMid + BTK inhibitor } \\
\quad+\text { Rituximab }\end{array}$ & Axillary Lymph Node & $\begin{array}{c}\text { TP53 } \\
\text { PIK3R2 } \\
\text { PTGS2 } \\
\text { STK36 } \\
\text { EZH2 } \\
\text { DNMT3A } \\
\text { PRKDC } \\
\text { ABL2 } \\
\text { AFF1 } \\
\text { BCL-2 } \\
\text { BCL-6 } \\
c-M Y C\end{array}$ & $\begin{array}{c}\text { Epigenetic regulation of } \\
\text { gene expression } \\
\text { Double-strand Break Repair } \\
\text { CD28 dependent PI3K/Akt } \\
\text { signaling } \\
\text { Pre-NOTCH Transcription } \\
\text { and Translation } \\
\text { TP53 Dependent G1 DNA } \\
\text { Damage Response }\end{array}$ & $\begin{array}{l}\text { 1. Epigenetic Therapy (e.g., } \\
\text { EZH2 or DNMT3A } \\
\text { inhibitor) } \\
\text { 2. PI3K } \\
\text { inhibitor + anti-CD20 Mab } \\
\text { 3. STK36 Hedgehog } \\
\text { pathway3. CAR-T }\end{array}$ \\
\hline
\end{tabular}




\begin{tabular}{|c|c|c|c|}
\hline \multicolumn{3}{|c|}{ Background } & \multirow[b]{2}{*}{$\begin{array}{l}\text { Mutations } \\
\text { CSMD3 } \\
\text { CDKN2A } \\
\text { MAGI1 } \\
\text { CREBBP } \\
\text { DOT1L } \\
\text { PBX1 } \\
\text { PRKDC } \\
\text { *LosS of ALK } \\
\text { translocation }\end{array}$} \\
\hline \multicolumn{3}{|c|}{$\begin{array}{l}\text { CB is a } 52 \text { year-old Caucasian female } \\
\text { nonsmoker with stage IV ALK- positive } \\
\text { NSCLC. The patient failed crizotinib } \\
\text { therapy and was placed on a phase 1b } \\
\text { trial of crizotinib plus AT13387, a heat } \\
\text { shock protein } 90 \text { (HSP90) inhibitor. After } \\
8 \text { cycles of therapy, no measurable } \\
\text { disease but persistent malignant right } \\
\text { pleural effusion. Molecular analysis } \\
\text { performed on pleural fluid. }\end{array}$} & \\
\hline \multicolumn{4}{|c|}{ Reactome identifies common pathways based on mutation signature: } \\
\hline CREBBP;PRKDC & \multicolumn{3}{|c|}{ Cytosolic sensors of pathogen-associated DNA } \\
\hline CDKN2A:CREBBP & \multicolumn{2}{|c|}{ Cellular responses to stress } & \multirow{2}{*}{ Clinical Implications } \\
\hline PRKDC & \multicolumn{2}{|c|}{ Double-Strand Break Repair } & \\
\hline CREBBP & \multicolumn{2}{|c|}{ RORA activates circadian gene expression } & \multirow{3}{*}{$\begin{array}{l}\text { 1. Alternate mechanisms of } \\
\text { resistance to crizontinib } \\
\text { therapy identified. }\end{array}$} \\
\hline CREBBP & \multicolumn{2}{|c|}{ REV-ERBA represses gene expression } & \\
\hline$C D K N 2 A$ & \multicolumn{2}{|l|}{ G1 Phase } & \\
\hline$C D K N 2 A$ & \multicolumn{2}{|c|}{ Oncogene-Induced Senescence } & 2. Loss of $A L K$-rearrangement. \\
\hline CREBBP & \multicolumn{2}{|c|}{ YAP1 and WWTR1 (TAZ)-stimulated gene expression } & \multirow{3}{*}{$\begin{array}{l}\text { 3. Reactome highlights } \\
\text { common pathways among new } \\
\text { mutation signature to guide } \\
\text { further targeted therapy. }\end{array}$} \\
\hline$C D K N 2 A$ & \multicolumn{2}{|c|}{ Cyclin-D-associated events in G1 } & \\
\hline CREBBP & \multicolumn{2}{|c|}{ Pre-NOTCH transcription and translation } & \\
\hline
\end{tabular}

Figure 6. Targetable signaling pathways with of loss EML4-ALK in a patient (Case \#9) with non-small cell adenocarcinoma of the lung cancer (Case \#9) progressing on crizotinib plus an HSP90 inhibitor.

Case \#3 is a patient with CUPS harboring a rare CCNE1 mutation treated with a CDK4/6 inhibitor on a clinical trial. The patient achieved stable disease for 11 months. In the cell cycle, cyclin E1 complexes with and activates CDK2 driving cells through the G1/S phase and is degraded as cells progress through S phase. Over-expression of CCNE1 has been found in many tumor types and can cause chromosome instability with enhanced proliferation. CCNE1/CDK2 phosphorylates NPAT (nuclear protein mapped to the ATM locus), a transcriptional activator of the cell cycle regulated histone gene expression promoting cell cycle progression in the absence of pRB [24]. In case \#3, mutated CCNE1 with a high proliferative index suggests that CDK4/ 6 inhibition could prevent G1 progression and halt cell cycling. In addition to a CCNE1 mutation, concurrent mutations in AKT3 and PTEN were present, suggesting co-targeting with a PI3K or mTOR inhibitor.

Case \#10 is a patient with triple-hit diffuse large B-cell lymphoma (MYC/BCL2/BCL6 translocated). The patient received dose-adjusted R-EPOCH immuno-chemotherapy with rapid progression and was enrolled on a novel-novel investigational trial of a BTK inhibitor + fourth generation IMiD + rituximab. The molecular profile prior to initiating therapy (Table 5) indicated multiple pathway defects including a TP53 dependent G1-aberrant DNA damage response. Drugs targeting epigenetics (e.g., EZH2 or DNMT3A inhibitor), DNA damage response and aberrant cell cycle may have benefitted this patient.

\section{Discussion}

The frequency and distribution of mutant oncogenes and tumor suppressors have redefined taxonomy for most tumor types. The mutational landscape of cancer is made up of a few mutated genes in a high fraction of tumors ('mountains') and most genes are altered at relatively low frequencies ('hills') [25]. Precision medicine approaches have been evaluated as novel tailored therapies and current trends emphasize characterizing the mutational repertoire. The questions remain as to what constitutes the 'driver pathways' that should be targeted. We focused our efforts on a heterogeneous group of cancer patients with metastasis entering early phase investigational agent trials. These patients have had $>3$ prior therapies. We provide an analysis of TP53 mutations present at primary and metastatic sites with other genomic aberrations that may guide rational targeted therapeutics. Tp53 current state-of-the-art precludes testing of TP53 mutant driven transcriptional programs with selective agent (s), since there is a lack of knowledge of these signaling pathways. Individual patients treated on targeted trials are subject to potential 
selection bias, however, our analyses highlight examples of decision complexity based on molecular profiling.

The mutational profiling of metastatic sites by NGS identify unique genetic aberrations absent at the primary site. Hence, to fully decipher pathobiology and therapeutic response, clonal and sub-clonal genotypes of individual tumors need characterization. Large-scale NGS projects require integration with functional screens to better develop strategies for novel therapeutic combinations. For functional screening to be useful, key metastatic drivers need to be identified to better define driver pathways that can be optimally targeted in anticipation of drug resistance and tumor evolution [26]. We utilized TP53 mutations as a critical driver at primary and metastatic sites and hypothesized that mutant p53 protein (s) activate unique signaling pathways within a background of epistasis [27]. Our study demonstrates that the enrichment of TP53 mutations occur at both primary and metastatic sites. This indicates both truncal and acquired TP53 mutations are most likely from prior therapies. The premise we surmised was that multiple epistatic mutations can have a combination effect, which differs from those they may elaborate individually. We identified TP53 mutations that may partner with unique co-mutations in colon and lung cancer. There has been a significant effort to restore wild type p53 function [28] in tumors with mutant TP53. Phase 1/II clinical trials are ongoing investigating small molecule inhibitors APR-246 (eprenetapopt binds to p53 at two cysteine residues in the DNA-binding domain and stabilizes mutant p53), PRIMA-1 (p53 reactivation and induction of apoptosis) and MDM2 inhibitor AMG 232 that restores p53 tumor suppression by blocking the MDM2-p53 interaction [29]. These p53 targeted small molecular inhibitors are being developed in both solid and hematologic malignancies. These inhibitors are available for testing in TP53 mutant cell lines and preclinical models to evaluate combination treatments targeting co-occurring gene mutations identified in our study.

In our analyses, we found co-mutations in the DNA damage repair genes (ATM, BRCA2, PRCKDC, PMS2) that highlight consideration for targeting with PARP inhibitors. Mutation in genes that activate multiple signaling pathways for e.g., mTOR and its inhibition by everolimus is a pharmacologic approach to target mutant TP53 reported to be activated in breast and pancreatic cancer cell lines. Similarly, histone lysine methyltransferases are known to modulate the methylation status of TP53 at distinct sites. Mutations in KMT2C/KMT2D can be targeted with specific methyltransferase small molecule inhibitors that disrupt the WDR5-KMT2 interaction [30]. Some of these core complex mutations along with TP53 mutations that upregulate the activation of specific cellular pathways can only be investigated by whole genome transcription assays in the backdrop of specific TP53 mutations. We believe that this is a basis for the transcriptomic studies of primary versus metastasis that could translate into unique 'pathway' focused therapies.

The current practice focus has been on mutations considered to be clinically 'actionable'. Comparative analyses of unmatched and matched primary and metastatic sites have shown depletion versus enrichment of certain oncogenic and tumor suppressor mutations respectively [16]. There appears to be a paucity of universal mutations limited to metastatic sites. However, focusing on distinct non-actionable TP53 mutations that drive unique signaling pathways may address context of vulnerability and define improved methods for rational therapies. These improved methods of rational combinations may help overcome acquired drug resistance at both primary and metastatic sites. It is prudent to develop transcriptional models to identify signaling pathway drivers. Tumor vulnerabilities differ based on specific TP53 mutations and tumor type, thus multi-mutant, multi-omics strategies are needed to elucidate cancer protecting activities that can be targeted. The goal of precision medicine in oncology will then move a step closer to the realization of implementing unique clinical trials personalized to each patient's malignancy. These trials will be key to assess targetable and non-targetable genomic aberrations and provide a handle on moving the needle to enhance survival in patients with metastatic disease. 


\section{Materials and Methods}

\subsection{Patient Population}

Patients with advanced solid and hematologic malignancies that were referred to the New Therapeutics Program $(n=203)$ were routinely profiled as a standard of care utilizing commercial next generation sequencing (NGS) platforms. Tumor samples taken from primary and metastatic sites (liver, lung, lymph nodes, pleural fluid, etc.) were formalinfixed and paraffin-embedded (FFPE). Ten case studies of patients' pre-/post-targeted treatment biopsies were available for analysis. All patient information was de-identified.

\subsection{Profiling Platforms}

We utilized Precipio 421-NGS (includes FISH) (Precipio Diagnostics, New Haven, CT, USA), Caris-Molecular Intelligence (600-NGS, IHC, FISH/CISH) (Caris Life Sciences, Irving, TX, USA), and Foundation One (300-NGS/CNV) (Foundation Medicine, Cambridge, MA, USA) platforms for NGS analysis. Each commercially available platform cannot be compared to each other as they are propriety encrypted; however, all the actionable genes are represented in each of the platforms. Biopsy samples were annotated by histology, primary and metastatic site, biopsy location, gene mutation, mutation count/gene and TP53 mutations. We focused on mutations that co-occur with mutant TP53 type at primary and metastatic sites. NGS molecular profiles from each patient and tumor type were categorized into common and unique mutations.

\subsection{Mutation Analysis in Primary and Metastatic Tissue Samples}

Out of 171 cases, gene mutations from 145 unique patient cases (94 with metastatic tumors and 51 with primary tumor) were analyzed. The mutation frequency and enrichment of mutation was estimated independently in primary and metastatic tumors. Relative frequency was calculated, and binomial exact test was performed to estimate the probability of enrichment of gene mutations in primary or metastatic tumors. For each gene mutation, the odds ratio was calculated as relative frequency of a gene mutation to the reference as average relative frequency of all genes. For all analysis $p$ value $<0.05$ was considered significant. Data was also stratified for organ specific mutations and similar analysis was performed to estimate frequency and enrichment. All analysis and plots were done utilizing $\mathrm{R}(\mathrm{v}$ 3.4.3).

\subsection{Gene Mutation Pathways and Protein Interaction}

Cytoscape (http:/ / www.cytoscape.org/) was used for the mapping of gene mutation frequencies and enrichment probability to cancer histology and primary site. We utilized Enrichr [31] to estimate enrichment of Reactome pathways [32] for gene mutations with significant representation across all patients. Signaling pathways were also estimated for primary and metastatic samples from specific primary sites using the enrichKEGG and cluster profiler package from Bioconductor (https:/ / Bioconductor.org). Top genes with mutations that were significant in tissue sites were analyzed for enriched Kegg pathways to find out which cellular pathways are altered by co-occurring gene mutations. Patients enrolled in targeted therapy trials were profiled pre-and/or post-treatment for pathway to ascertain response to therapy. Protein interaction analysis was performed using the String database [33].

\subsection{Three-Dimensional Mapping}

The crystal structure of p53 bound to DNA from Protein Data bank (pdb: 3KZ8) was utilized to map TP53 mutations [20]. The International Agency for Research on Cancer (IARC - Version R 19) TP53 database was used to help analyze data on human cancer TP53 gene variations [21]. 


\section{Conclusions}

The mutational profiling of primary and metastatic sites of cancer patients participating in early phase therapeutic trials provide an opportunity to identify distinct TP53 mutations that drive unique signaling pathways, which should guide rational drug combinations to abrogate oncogene addiction and drug resistance, hopefully with minimal toxicity to normal tissue.

Supplementary Materials: The following are available online at https:/ / www.mdpi.com/2072-669 4/13/4/597/s1. Figure S1: The crystal structures of p53 bound to DNA was utilized to map common and rare p53 mutations detected in our cohort of patients. Figure S2: TP53 protein interaction network from String $\mathrm{db}$.

Author Contributions: D.M.-Design, execution, analysis, and writing of the manuscript; R.P.Data Analysis, Bioinformatics, statistical analysis, wrote part of the manuscript; Y.C.-Data and statistical Analysis, N.J.-Methodology and analysis of data; B.J.-Methodology and wrote part of the manuscript; M.P.- - Reviewed molecular profiling data and wrote sections of the manuscript; J.C.--Reviewed molecular profiling data and wrote sections of the manuscript; L.C.-Wrote parts of the manuscript, generated Tables, structural models of $\mathrm{p} 5$ and pathway analysis. All authors have read and agreed to the published version of the manuscript.

Funding: This research was funded by discretionary funds from University of TN Health Science Center.

Institutional Review Board Statement: Ethical review and approval were waived for this study, due to the fact that commercially available platforms were used to research tumor profiling with de-identified samples which does not require ethics committee approval as no patient information is used.

Informed Consent Statement: Patient consent was waived due to: No patient information was used and de-identified patient samples were used for tumor profiling.

Data Availability Statement: The data presented in this study are available within the article or supplementary material.

Acknowledgments: We wish to thank the West Clinic and the University of Tennessee Health Science Center for support and seed funding.

Conflicts of Interest: The authors listed have no conflict of interest or financial disclosures.

\section{References}

1. The International Cancer Genome Consortium. International network of cancer genome projects. Nature 2010, 464, 993-998. [CrossRef] [PubMed]

2. Garraway, L.A.; Lander, E.S. Lessons from the cancer genome. Cell 2013, 153, 17-37. [CrossRef] [PubMed]

3. Stratton, M.R. Journeys into the genome of cancer cells. EMBO Mol. Med. 2013, 5, 169-172. [CrossRef] [PubMed]

4. Gerlinger, M.; Horswell, S.; Larkin, J.; Rowan, A.J.; Salm, M.P.; Varela, I.; Fisher, R.; McGranahan, N.; Matthews, N.; Santos, C.R.; et al. Genomic architecture and evolution of clear cell renal cell carcinomas defined by multiregion sequencing. Nat. Genet. 2014, 46, 225-233. [CrossRef] [PubMed]

5. Swanton, C. Cancer evolution: The final frontier of precision medicine? Ann. Oncol. 2014, 25, 549-551. [CrossRef] [PubMed]

6. NCT01888601. Available online: http://clinicaltrials.gov/show / NCT01888601 (accessed on 1 December 2020).

7. Cancer Research UK News. Available online: http://www.cancerresearchuk.org/about-us/cancer-news/press-release/newresearch-to-revolutionise-understanding-of-lung-cancer (accessed on 18 July 2013).

8. Larson, K.; Kannaiyan, R.; Pandey, R.; Chen, Y.; Babiker, H.M.; Mahadevan, D. A Comparative Analysis of Tumors and Plasma Circulating Tumor DNA in 145 Advanced Cancer Patients Annotated by 3 Core Cellular Processes. Cancers 2020, $12,701$. [CrossRef] [PubMed]

9. MacConaill, L.E. Existing and emerging technologies for tumor genomic profiling. J. Clin. Oncol. 2013, 31, 1815-1824. [CrossRef]

10. Schott, A.F.; Perou, C.M.; Hayes, D.F. Genome Medicine in Cancer: What's in a name? Cancer Res. 2015, 75, 1930-1935. [CrossRef]

11. Conley, B.A.; Doroshow, J.H. Molecular analysis of therapy choice: NCI MATCH. Semin. Oncol. 2014, 41, 297-299. [CrossRef]

12. NCI-MPACT: Molecular Profiling-Based Assignment of Cancer Therapy for Patients with Advanced Tumors. 2014. Available online: http:/ / clinicaltrials.gov/show/NCT01827384 (accessed on 1 December 2020).

13. Schilsky, R.L. Implementing personalized cancer care. Nat. Rev. Clin. Oncol. 2014, 11, 432-438. [CrossRef]

14. Garraway, L.A. Genomics-driven oncology: Framework for an emerging paradigm. J. Clin. Oncol. 2013, 31, 1806-1814. [CrossRef]

15. Heuckmann, J.M.; Thomas, R.K. A new generation of cancer genome diagnostics for routine clinical use: Overcoming the roadblocks to personalized cancer medicine. Ann. Oncol. 2015, 26, 1-8. [CrossRef] [PubMed] 
16. Birkbak, N.J.; McGranahan, N. Cancer Genome Evolutionary Trajectories in Metastasis. Cancer Cell. 2020, 37, 8-19. [CrossRef] [PubMed]

17. Mantovani, F.; Collavin, L.; Del Sal, G. Mutant p53 as a guardian of the cancer cell. Cell Death Differ. 2019, 26, 199-212. [CrossRef] [PubMed]

18. Rao, R.C.; Dou, Y. Hijacked in cancer: The KMT2 (MLL) family of methyltransferases. Nat. Rev. Cancer 2015, 15, 334-346. [CrossRef]

19. Khan, Z.A.; Jonas, S.K.; Le-Marer, N.; Patel, H.; Wharton, R.Q.; Tarragona, A.; Ivison, A.; Allen-Mersh, T.G. P53 mutations in primary and metastatic tumors and circulating tumor cells from colorectal carcinoma patients. Clin. Cancer Res. 2000, 6, 3499-3504.

20. Kitayner, M.; Rozenberg, H.; Rohs, R.; Suad, O.; Rabinovich, D.; Honig, B.; Shakked, Z. Diversity in DNA recognition by p53 revealed by crystal structures with Hoogsteen base pairs. Nat. Struct. Mol. Biol. 2010, 17, 423-429. [CrossRef]

21. Bouaoun, L.; Sonkin, D.; Ardin, M.; Hollstein, M.; Byrnes, G.; Zavadil, J.; Olivier, M. TP53 Variations in Human Cancers: New Lessons from the IARC TP53 Database and Genomics Data. Hum Mutat. 2016, 37, 865-876. [CrossRef]

22. Muller, P.A.J.; Vousden, K.H. Mutant p53 in Cancer: New Functions and Treatment Opportunities. Cancer Cell 2014, 25, 304-317. [CrossRef]

23. Giri, S.; Patel, J.K.; Mahadevan, D. Novel mutations in a patient with ALK-rearranged lung cancer. N. Engl. J. Med. 2014, 371, 1655-1656. [CrossRef]

24. Mazumder, S.; DuPree, E.L.; Almasan, A. A dual role of cyclin E in cell proliferation and apoptosis may provide a target for cancer therapy. Curr. Cancer Drug Targets 2004, 4, 65-75. [CrossRef] [PubMed]

25. Hanahan, D.; Weinberg, R.A. Hallmarks of cancer: The next generation. Cell 2011, 144, 646-674. [CrossRef] [PubMed]

26. Natrajan, R.; Wilkerson, P. From integrative genomics to therapeutic targets. Cancer Res. 2013, 73, 3483-3488. [CrossRef] [PubMed]

27. Cui, H.; Dhroso, A.; Johnson, N.; Korkin, D. The variation game: Cracking complex genetic disorders with NGS and omics data. Methods 2015, 79-80, 18-31. [CrossRef] [PubMed]

28. Bykov, V.J.; Wiman, K.G. Mutant p53 reactivation by small molecules makes its way to the clinic. FEBS Lett. 2014, 588, 2622-2627. [CrossRef]

29. Canon, J.; Osgood, T.; Olson, S.H.; Saiki, A.Y.; Robertson, R.; Yu, D.; Eksterowicz, J.; Ye, Q.; Jin, L.; Chen, A.; et al. The MDM2 Inhibitor AMG 232 Demonstrates Robust Antitumor Efficacy and Potentiates the Activity of p53-Inducing Cytotoxic Agents. Mol. Cancer Ther. 2015, 14, 649-658. [CrossRef]

30. Senisterra, G.; Wu, H.; Allali-Hassani, A.; Wasney, G.A.; Barsyte-Lovejoy, D.; Dombrovski, L.; Dong, A.; Nguyen, K.T.; Smil, D.; Bolshan, Y.; et al. Small-molecule inhibition of MLL activity by disruption of its interaction with WDR5. Biochem. J. 2013, 449, 151-159. [CrossRef]

31. Chen, E.Y.; Tan, C.M.; Kou, Y.; Duan, Q.; Wang, Z.; Meirelles, G.V.; Clark, N.R.; Ma'ayan, A. Enrichr: Interactive and collaborative HTML5 gene list enrichment analysis tool. BMC Bioinform. 2013, 14, 128. [CrossRef]

32. Fabregat, A.; Jupe, S.; Matthews, L.; Sidiropoulos, K.; Gillespie, M.; Garapati, P.; Haw, R.; Jassal, B.; Korninger, F.; May, B.; et al. The Reactome Pathway Knowledgebase. Nucleic Acids Res. 2018, 46, D649-D655. [CrossRef]

33. Szklarczyk, D.; Gable, A.L.; Lyon, D.; Junge, A.; Wyder, S.; Huerta-Cepas, J.; Simonovic, M.; Doncheva, N.T.; Morris, J.H.; Bork, P.; et al. Protein-protein association networks with increased coverage, supporting functional discovery in genome-wide experimental datasets. Nucleic Acids Res. 2019, 47, D607-D613. [CrossRef] 